13

\title{
Импульсные и статические автоэмиссионные BAX-углеродных нанокластерных структур: эксперимент и его интерпретация
}

\author{
(C) М.В. Давидович, ${ }^{1,2}$ P.К. Яфраров ${ }^{1,2}$ \\ ${ }^{1}$ Саратовский национальный исследовательский государственный университет им. Н.Г. Чернышевского, \\ 410012 Саратов, Россия \\ ${ }^{2}$ Саратовский филлиал ИРЭ РАН им. В.А. Котельникова, \\ 410054 Саратов, Россия \\ e-mail: davidovichmv@info.sgu.ru
}

Поступило в Редакцию 19 ноября 2018 г.

В окончательной редакции 19 ноября 2018 г.

Принято к публикации 21 февраля 2019 г.

Рассмотрены автоэмиссионные свойства углеродных нанокластерных структур и пленок на их основе, приведены экспериментальные данные, в том числе ВАХ, при статическом и импульсном режимах. Проведен анализ размерных эффектов, эффекта проникновения поля, эффекта гистерезиса. Даны их теоретические объяснения.

Ключевые слова: автоэлектронная эмиссия, алмазографитовые нанокластерные пленки, вольт-амперные характеристики, импульсная полевая эмиссия, отрицательное электронное сродство, размерные эффекты, резонансное туннелирование.

DOI: $10.21883 / J T F .2019 .08 .47905 .402-18$

\section{Введение}

Повышенные автоэмиссионные свойства различных углеродных структур в последнее время привлекают внимание исследователей в связи с необходимостью создания сильноточных автоэмиссионных источников электронных пучков [1-5], и этим вопросам посвящено значительное число публикаций, например, [6-41]. Имеются работы как по исследованию автоэмиссионных структур (AC) острийного и лезвийного типов [7,16-20,23-25], в том числе с катодными матрицами типа Спиндта с тянущими сетками [3,5,24], использующие эффект усиления поля на остриях и лезвиях, так и работы по исследованию эмиссии с пространственно развитых поверхностей $[1,2,8-12,15,20-22,26-30,33-36]$, публикации по технологии и синтезу эмиссионных структур [6-13,21,26-31,33], экспериментальному [2,5-7,12,14-39] и теоретическому исследованию автоэлектронной эмиссии (АЭ) [6,29,37,38,40-47]. Существуют два основных направления создания высокоточных источников на АЭ. Первое следует Спиндту и направлено на конструирование острийных структур с большим числом острий или лезвий. Их работа основана на усилении поля. Второе основано на создании пространственно развитых поверхностей с АЭ почти со всех их элементов. Использование сеточных структур возможно в обоих случаях и позволяет снижать напряжения и эффективно управлять эмиссией. Катоды Спиндта на стеклоуглероде [1,23-25] и углеродные нанотрубки (УНТ) [1,5] подвержены сильной деградации из-за высоких значений полей, плотностей токов, пондеромоторных сил и сильной ионной бомбардировки на эмитирующих участках, что ведет к их ускоренному разрушению. Для второго направления используют углеродные нанокластеры различной гибридизации, которые могут быть расположены на графите, металле, кремнии, карбиде кремния и других материалах. Интересны наноалмазные, нанографитовые и алмазографитовые пленки (АГП) [1,2,6,8-10,15,20-22,26-31,34-47]. Пленки из наноалмазных кластеров являются почти диэлектрическими. Такие структуры обладают высокой пористостью, высоким значением удельной поверхности (отношением поверхности к массе), сильным проникновением поля в структуру [44-47]. Соответственно имеет место большое число поверхностных таммовских уровней существенно выше энергии Ферми катода $[26,27,46,47]$, значительный коэффициент усиления поля $\beta$. В качестве пространственно развитых поверхностей для АЭ можно использовать слои графена на $\mathrm{SiO}_{2}$, структуры из стеклоуглерода, структуры типа графен-нанотрубки [1,48-51], включая колонный графен [50,51] (рис. 1).

Известные АC острийного и лезвийного типов не удовлетворяют ряду требований для источников с большим током [1,3-5]. В острийных автокатодах эмиссия идет в основном с острий, разогрев которых приводит к взрывной эмиссии и не позволяет получать большие интегральные значения тока и долговечные катоды. Матричные автокатоды создают большой разброс электронов по углам и не позволяют получать широкие и тонкие ленточные пучки. Они сложны в изготовлении. Лезвийные автокатоды дают высокую локальную плотность тока, но не позволяют получать большие интегральные токи. Для получения тонких высокоточных пучков нужна их компрессия. АЭ-структуры с развитой поверхностью в виде алмазографитовых нанокластеров 
$a$
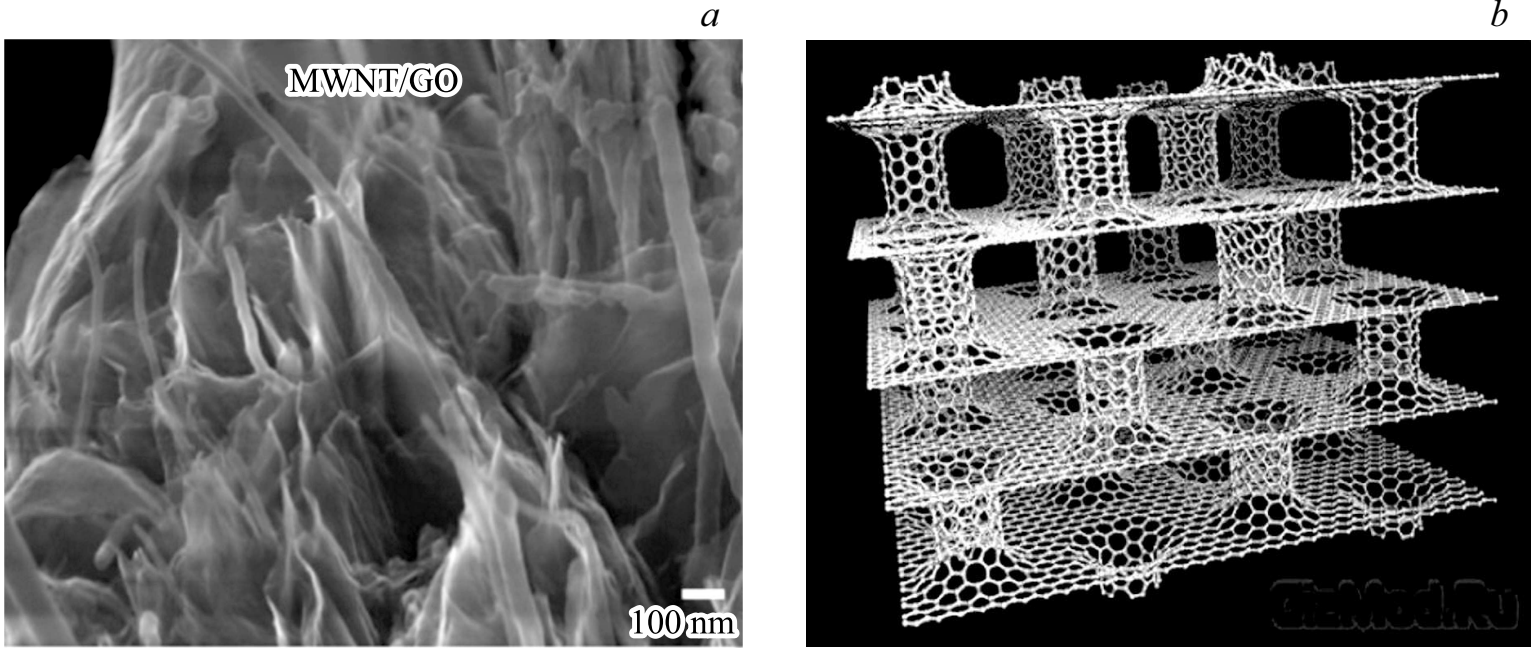

CNT-graphene hydrid

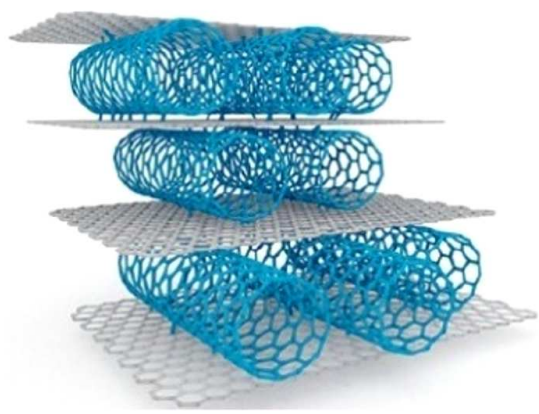

Рис. 1. $a$-АСМ-фотографии (сверху) и модели $2 D$-пленок гибридного УНТ-графен композита типа стеклоуглерод с параллельными друг другу УНТ, ковалентно связанными с графеновыми монослоями [48,49]; $b$ - многослойные графеновые листы, соединенные с УНТ (колонный графен) [50,51].

(АГН) обладают хорошей устойчивостью к деградации, поскольку перемещение последних и даже взрывная эмиссия с них не изменяют структуру поверхности. Малый радиус кривизны нанокластеров с размерами в несколько нанометров способствует усилению поля, увеличение поверхности по сравнению с атомарно плоской поверхностью металлических АЭ-катодов создает большое число поверхностных уровней, увеличивающих эмиссию. Наноалмазные кластеры способствуют проникновению поля в пространственно развитую поверхность, что также способствует эмиссии [45]. Этому же способствуют рельефные структуры, полученные травлением [29]. Однако коэффициент усиления поля в них недостаточен для объяснения АЭ с помощью теории Фаулера-Нордгейма [46]. Формула Фаулера-Нордгейма $(\Phi \Phi Н)$, полученная для удаленного анода и плоской идеально проводящей поверхности на основе зеркальных изображений и квазиклассического (ВКБ) приближения для туннелирования, не работает для углеродных структур [35-38,46,52]. Для них имеет место пористость и проникновение поля внутрь через поверхность. Во всяком случае, оценка работы выхода (РВ) по ФФН дает заниженное на 1-2 порядка значение (в пределах от 0.01 до $0.4 \mathrm{eV}$, т. е. существенно меньшее $1 \mathrm{eV}$ ), тогда как расчеты на основе квантовой механики (квантовой химии) дают для всех структур значения РВ в диапазоне 4-5 eV. Учет эмиссии в вакуумном диоде при аноде на конечном расстоянии получен в [43]. Учет АЭ для конфигурации с анодом и диэлектрической пленкой на катоде - в работах [39-42]. Там же получены соотношения для вакуумного триода. Имеется большое число публикаций по АЭ из пленок с наноалмазными, нанографитовыми кристаллитами, из композитных и аморфных углеродных пленок (см., например, литературу в [46]). В значительном числе работ имеют место объяснения низкопороговой АЭ, а в ряде приведены принципиально различные модели. В работах [39-42] влияние тонкой пленки на туннельный эффект учтено методом многократных изображений. Показано, что при большой диэлектрической проницаемости (ДП) возникающий барьер имеет сложную двойную форму, мал на границе проводник-пленка, на большей части пленки спадает, и основной барьер возникает на границе пленка-вакуум. Он существенно уже и ниже барьера на границе проводник-вакуум без пленки. Модель работает для плоской однородной диэлектрической пленки, когда ее толщина меньше длины 
свободного пробега в ней. Усиление эффекта наблюдается для триодной структуры с малым расстоянием сеткаанод, когда основное падение напряжения имеет место в вакуумном зазоре. Наклон профиля потенциала связан с проникновением поля в пленку и с ускорением электрона, движущегося к барьеру. В работах $[53,54]$ эффект для допированной азотом пленки объяснен отрицательным электронным сродством, в работе [55] для АГП наличием проводящих каналов. АЭ через пленки аморфных полупроводников рассмотрена в работах [56-58]. Объяснение низкопороговой АЭ связано с образованием барьеров типа Шоттки и квантовых ям при допировании, в частности, азотом и серебром. В работах $[59,60]$ установлена разность температур электронов при эмиссии из проводника через пленку и с поверхности пленки, т.е. доказана многоканальная АЭ. Ряд механизмов и моделей обсуждается в одном из первых обзоров по низкопороговой эмиссии из углеродных пленок [44]. В нем и в ряде других работ, например, [61,62], рассмотрено образование и влияние кластеров и проводящих каналов, ступенчатое туннелирование через барьеры сложной формы и ряд других эффектов. Эффект проникновения поля в пленку рассмотрен в работах [45] и в [63]. В последней также рассмотрен ряд квантоворазмерных эффектов, связанных с толщиной пленки, а также с резонансным туннелированием через слоистую катодносеточную структуру. В работах $[35,36]$ показано, что повышенная АЭ из углеродных структур не связана с острийным эффектом усиления поля, хотя фактор усиления $\beta$ следует учитывать и для пространственно развитых структур с острыми кромками и кластерами малого радиуса. В работе [36] эффект увеличения ПЭ объяснен резонансным туннелированием в результате размерного квантования при образовании уровней, совпадающих с уровнем Ферми. Размерное квантование изменяет профиль потенциального барьера, в результате возникают дополнительные поверхностные уровни. Если их много и они выше уровня Ферми массивного образца, то РВ (высота барьера при данном потенциале) понижается. Если на поверхности расположены нанокластеры, образующие структуру с толщиной порядка от нескольких до десятков нанометров, то также создаются дополнительные уровни. Их тем больше, чем меньше радиус (размер) кластеров, обратная величина которого определяет отношение поверхности к объему. Модель на основе квантовой механики для туннелирования в тонкой (порядка нанометра) оксидной пленке $\mathrm{SiO}_{2}$ на $\mathrm{Si}$ приведена в [64]. Использован зонный подход к описанию пленки как широкозонного полупроводника, хотя вызывает сомнение возможность формирования зонной структуры в такой тонкой пленке. Во всяком случае, необходима толщина порядка и более нескольких длин свободного пробега. Тестовые расчеты в [64] не дали однозначных результатов. Использование строгих подходов на основе квантовой механики со времени основополагающей работы [65] сильно продвинулось, особенно в плане определения РВ (потенциалов ионизации) углеродных и ряда других структур на основе модельных потенциалов метода сильной связи и теории функционала плотности [49-51]. Влияние тонкой оксидной пленки на АЭ было установлено на заре создания теории туннелирования [66]. Именно, тонкая диэлектрическая пленка способствует туннелированию [67], тогда как толстая препятствует ему, создавая высокий и широкий потенциальный барьер, поскольку электронам с энергией Ферми $E_{F}$ соответствует широкая (до уровня свободного электрона) запрещенная зона диэлектрика. Этим, в частности, объясняются изолирующие свойства диэлектриков. Ясно, что существует оптимальная толщина, как и оптимальные размеры кластеров, их концентрации полупроводниковой и диэлектрической $\left(s p^{2}-s p^{3}\right)$ фаз включений в пленках, что и должно определять модель АЭ. Экспериментально АЭ исследована из различных углеродных структурах, расположенных на проводящей поверхности катода: из фуллеренов, УНТ, графеновых чешуек, стеклоуглерода, алмазных и графитовых нанокластеров, астраленов и наноторов, из комбинированных структур графенов и нанотрубок, из напыленных пленок, состоящих из АГН. Практически для всех структур методом сильной связи и на основе теории функционала плотности рассчитаны энергетические структуры и потенциалы ионизации, которые лежат в районе 4.5-4.7 eV. Углерод демонстрирует наибольшее число аллотропных модификаций, обладающих существенно отличающимися свойствами и разнообразием электронной структуры, что обусловлено различным соотношением $s p-, s p^{2}-$ и $s p^{3}$-гибридизованных атомов. Он реализует диапазон электропроводности от диэлектрика - изолирующего алмаза - до металлического графита. Внутри этого ряда находятся такие модификации, как сажа, черный уголь, карбин, фуллерены, однослойные и многослойные УНТ, углеродные нити, графеновые нановолокна, структуры типа „рыбьи кости“, „папье-маше“, пучки, пряди, веревки, жгуты, рулоны, обручи, тороиды, конуса, „рожки“, „Луковицы“, „матрешки“, „гороховые стручки“ [68], а также разнообразные структуры аморфного углерода (стеклоуглерода). Проводимость углеродных структур зависит от функционализации (допировании) разными атомами типа $\mathrm{O}, \mathrm{H}, \mathrm{N}, \mathrm{Ag}$ и др. Стеклоуглерод имеет сильное различие в плотности (пористости) в зависимости от технологии получения и может состоять из различных кластеров: графеновых чешуек, нанотрубок, фуллеренов, их элементов и т.П. Пористость стеклоуглерода и структур из УНТ приводит к возможности проникновения поля. Повышенная АЭ наблюдается во всех аллотропных модификациях углерода, что, наряду с высокой теплопроводностью и прочностью, делает их весьма перспективными для создания сильноточных источников электронных пучков в приборах микроэлектроники и наноэлектроники. Устойчивость к разогреву и способность к самовосстановлению, препятствующая деградации эмитирующей поверхности при сильной эмиссии, являются привлекательными свойствами при создании катодов. Экспериментально показано, что одиночная 
графеновая пленка на металле не изменяет РВ [69,70], а заметные изменения происходят, когда число слоев порядка 10 и более, т. е. для толщин порядка $3 \mathrm{~nm}$ и более, что еще раз подтверждает существование оптимальной толщины покрытия катода.

В настоящей работе теоретически и экспериментально исследована АЭ и получены статические и динамические (импульсные) ВАХ диодных структур из АГП. Теоретически рассмотрены и ВАХ триодных структур, включая структуры с резонансным туннелированием. Результаты объяснены на основе квантово-размерных эффектов и эффекта проникновения поля в пористые структуры.

\section{Туннелирование через квантово-размерные пленки}

Коэффициент туннелирования $D=|T|^{2}$ в приближении ВКБ экспоненциально зависит от ширины $t=$ $=z_{2}-z_{1}$ барьера - расстояния между двумя точками поворота. Это видно для конкретных простых его форм. Для треугольного барьера в квазиклассическом приближении $D \approx\left(-2^{5 / 2}\left(\varphi^{3} m e\right)^{1 / 2} /\left(3 \eta e E_{z}\right)\right)$. Пусть $E_{k}=$ $=k_{0}^{2} \eta^{3} /(2 m)$ - кинетическая, а $V(z)$ - потенциальная энергии. Обозначая РВ $\varphi=\max \left(V(z)-E_{k}\right), \vartheta=k_{0} \xi t$, $\varepsilon_{b}=-\varphi / E_{k}, \quad \xi=\sqrt{\left|\varepsilon_{b}\right|}$, для прямоугольного барьера имеем $\quad T=\left[\cosh (\vartheta)-i\left(\xi-\xi^{-1}\right) \sinh (\vartheta) / 2\right]^{-1}$. Для широкого прямоугольного барьера $T \approx 2 \exp (-\vartheta) /[1-$ $-i\left(\xi-\xi^{-1}\right) / 2$ ]. Если $E_{k}>3 \varphi / 2$ (что обычно имеет место для $\left.E_{k} \sim E_{F}\right)$, то получаем $D=|T|^{2}=C \exp (-2 \vartheta)$, т.е. тоже имеем экспоненциальное затухание, причем $2<C<4$. Отсюда для $E_{F}=5 \mathrm{eV}, \varphi=3 \mathrm{eV}$ и $t=10 \mathrm{~nm}$ имеем оценку $D \approx 5.3 \cdot 10^{-87}$. Для сильной АЭ барьер существенно у́же.

Рассмотрим туннелирование в вакуумном диоде с пленкой диэлектрического типа на катоде толщины $t$. Потенциал изображений точечного заряда $q$ в точке его расположения в плоском конденсаторе размера $d$ имеет вид [43]

$$
U(z)=-\frac{q}{8 \pi \varepsilon_{0}}\left[\frac{1}{z}+2 \sum_{n=1}^{\infty}\left(\frac{n d}{(n d)^{2}-z^{2}}-\frac{1}{n d}\right)\right] .
$$

Сам заряд, естественно, на себя не действует. На электрон $q=-e$ действует сила $-e E_{z}(z)$, где $E_{z}(z)=-d U(z) / d z$, поэтому работа по перемещению электрона с катода равна

$$
W_{p}=-\frac{e^{2}}{16 \pi \varepsilon_{0}}\left[\frac{1}{z}+2 \sum_{n=1}^{\infty}\left(\frac{n d}{(n d)^{2}-z^{2}}-\frac{1}{n d}\right)\right] .
$$

Возникновение двойки в знаменателе можно объяснить тем, что на заряд вблизи идеального металлического экрана действует сила, пропорциональная квадрату удвоенного расстояния до него. Формула (2) дает бесконечную отрицательную потенциальную энергию

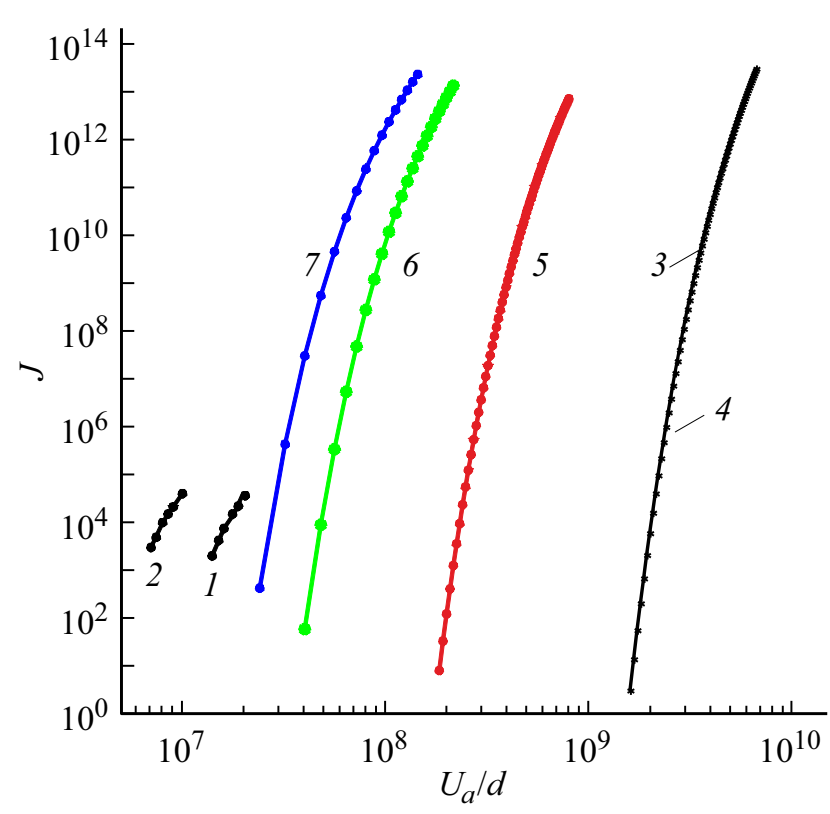

Рис. 3. Плотность тока $\left(\mathrm{A} / \mathrm{m}^{2}\right)$ в зависимости от отношения напряжения на диодной структуре к ее длине $d(\mathrm{~V} / \mathrm{m})$ : $d=120 \mu \mathrm{m}$ - кривые $1-3 ; d=20 \mathrm{~nm}-$ кривые $4-6$; кривая 1 - эксперимент для алмазографитовой пленки с 70\% алмазной фазы; кривая 2 - эксперимент для алмазографитовой пленки, покрытой алмазной пленкой $10 \mathrm{~nm}$; кривая 3 - структура без пленки; кривые 5 и 4 соответствуют барьеру 3 и 4, рис. 2, $a$; кривая 6 построена с учетом разогрева электронов на $0.3 \mathrm{eV}$ за счет наклонного к барьеру участка, а кривая 7 - для разогрева на $0.5 \mathrm{eV}$.

электрона на катоде. Это имеет место из-за того, что сила зеркального изображения бесконечна при нулевом расстоянии. На самом же деле эта сила перестает действовать на расстоянии порядка половины постоянной решетки кристалла, т.е. на расстоянии, когда электронные оболочки атомов перекрываются. Обозначим это расстояние $\delta$. Тогда потенциальная энергия электрона в вакуумном диоде есть

$$
\begin{aligned}
W_{p}=-\frac{e^{2}}{16 m \varepsilon_{0}} & {\left[\frac{1}{z+\delta}-\frac{2}{d}+\frac{1}{d+\delta-z}+\frac{1}{d+z}\right.} \\
& \left.+\frac{2 z^{2}}{d^{3}} \sum_{n=2}^{\infty} \frac{1}{\left(n^{2}-(z / d)^{2}\right) n}\right] .
\end{aligned}
$$

Ряд (3) весьма быстро сходится, а описываемая им функция симметрична относительно центра диода. В нем $W_{p}(d / 2)=-e \ln (2) /\left(4 \pi \varepsilon_{0} d\right)$ (при $\left.\delta \ll d\right)$. Полагая потенциальную энергию на катоде равной энергии Ферми, отсчитываемой от дна $-E_{0}$ зоны проводимости $W_{p}(0)=E_{F}-E_{0}$ и $d \rightarrow \infty$, получаем РВ из уединенного катода $W_{0}=e^{2} /\left(16 \pi \varepsilon_{0} \delta\right)$. Для металлов, отдающих один электрон в зону проводимости, эта формула хорошо коррелирует с потенциалом ионизации иона $+1 e$, если за $\delta$ взять радиус его электронной оболочки. Глубина зоны проводимости есть $E_{0}=E_{F}+W_{0}$. При большом 

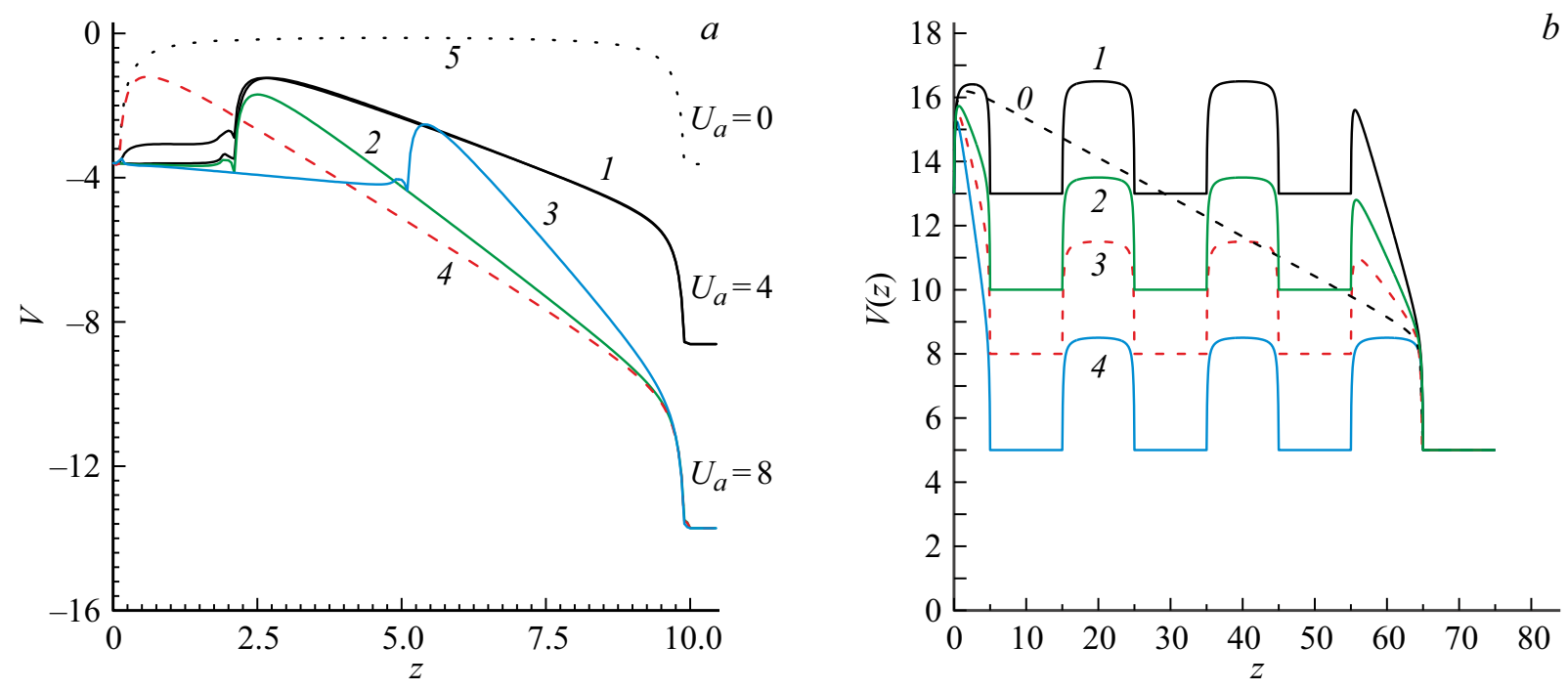

Рис. 2. Формы барьеров (распределения потенциалов $V$, $[\mathrm{eV}]$ в зависимости от длины $z$, [nm]) в диоде $(a)$ и триоде $(b)$. График $a$ : вакуумный диод длины $10 \mathrm{~nm}$ при напряжениях на аноде 4 (кривая 1$), 8(2-4)$ и $0 \mathrm{~V}$ (пунктирная кривая 5 ); кривые 1 и 5 построены без пленки, 2 и 3 для пленки толщины $2.5 \mathrm{~nm}, 4$ - для пленки $5 \mathrm{~nm}$. График $b$ : плоский вакуумный триод длины $65 \mathrm{~nm}$ с тремя сеточными электродами при $\varphi=3.6 \mathrm{meV}, E_{F}=5 \mathrm{eV}$, анодном напряжении $U_{a}=8 \mathrm{~V}$ и напряжениях на сетке $U_{g}=0$ (кривая 1 ), $U_{g}=3(2), U_{g}=5(3), U_{g}=8 \mathrm{~V}(5)$; ДП $\varepsilon=10$; штриховая кривая 0 соответствует диодной структуре без сетки; отсчет потенциала идет от дна зоны проводимости анода.

расстоянии катод-анод $W_{p}(d / 2) \approx 0$ и РВ $W \approx W_{0}$. В общем случае РВ связана с введенным параметром равенством $W=W_{p}(d / 2)-W_{p}(0)=W_{0}(1-2.772 \delta / d)$. Это та работа, которую нужно совершить, чтобы электрон достиг максимума барьера и перешел на анод (при нулевом напряжении на последнем). На границе диэлектрической пленки образуется наведенный поверхностный заряд, для учета которого следует использовать изображения типа ряда (1). Наличие пленки приводит к несимметричному барьеру, который также можно получить, используя изображения относительно двух металлических $(z=0$ и $z=d)$ и одной диэлектрической $(z=t)$ поверхностей. Изображения зависят от положения электрона внутри и вне пленки и определяются величиной ДП $\varepsilon$. Представление результата кратных изображений зависит от их порядка (очередности). Сам результат от этого не зависит. В частности, для поля заряда $q$ вне пленки ближайшее изображение внутри пленки имеет величину заряда $q^{\prime}=q(1-\varepsilon) /(1+\varepsilon)$. Заряд находится в точке $z>t$, а его изображение в точке $z^{\prime}=2 t-z$. Для поля заряда внутри пленки $z<t$ величина заряда изображения вне пленки (при $\left.z^{\prime \prime}=2 t+z\right)$ равна $q^{\prime \prime}=-q / \varepsilon$. В проводящей структуре имеет место почти полное экранирование заряда, что эквивалентно бесконечно большой по модулю ДП и $q^{\prime}=-q$. Это характерно для изображений относительно поверхности металла. Заряд и его изображения следует многократно отображать относительно поверхностей катода, анода и пленки. Для этого удобна формула (1), в которую следует подставлять величины $q$ и $q^{\prime}$ для области $t<z<d, q$ и $q^{\prime \prime}$ для области $0<z<t$ и брать суммы. Профиль барьера получается при $q=-e$ как работа по перемещению электрона с катода путем вычисления интеграла от силы, действующей на него со стороны изображений. Напряжение на аноде добавляет энергию $-e U_{a} z / d$ и приводит к образованию узкого несимметричного потенциального барьера с двумя всплесками на обеих границах (рис. 2,a). При большой ДП и напряжении $U_{a}$ максимальным будет барьер на границе диэлектрик-вакуум. Однако в толстой пленке широкозонного полупроводника может возникать двойной барьер. В такой пленке вид барьера (искривление энергетических зон) зависит от РВ массивного образца материала пленки и типа ее проводимости. Если эта РВ меньше РВ материала катода, возникает барьер типа Шоттки с донорным проводником, изгибающим зону вниз, а если больше - то контакт с акцепторным полупроводником, изгибающим зону вверх. Возможны четыре случая и типа изгибов зонной структуры: два вверх и два вниз для двух различных соотношений для PB. Однако при обычной разности РВ порядка $1 \mathrm{eV}$ ширина барьера Шоттки (области пространственного заряда) должна быть порядка микрона, поэтому для наноразмерной пленки барьер типа Шоттки полностью реализован быть не может, а профиль барьера может быть сложным. Он также зависит от того, является ли пленка кристаллической или аморфной, и от количества поверхностных уровней и примесей, уменьшающих электронное сродство. Важно получение малого или даже отрицательного электронного сродства [71], что возможно на кластерах $n$-типа. В простой модели тонкой диэлектрической пленки возникает только поверхностная плотность заряда на ее границах. При большом потенциале анода $U_{a}$ возникает наклон профиля к ба- 
рьеру, расположенному около границы с вакуумом, что означает ускорение электрона, набегающего на него, и лучшее туннелирование. При $U_{a}$ больше критического этот барьер может исчезнуть вовсе. При пленке, состоящей из разных кристаллитов, модель осложняется. Становится возможным туннелирование по нескольким каналам $[46,59]$. Модель работает при толщине пленки, существенно меньшей длины свободного пробега и отсутствия в ней свободных зарядов (дебаевского экранирования). Строгое решение задачи туннелирования через слабо проводящую полупроводниковую пленку требует согласованного решения уравнений Шредингера и Пуассона [72]. Это же относится и к нестационарному (импульсному) туннелированию, особенно при больших плотностях тока и заряда, при работе в периодических режимах и при малых пролетных длинах. Наличие чередования тонких диэлектрических и проводящих слоев приводит к возможности резонансного туннелирования, если потенциалы проводящих слоев одинаковы и эти слои образуют тянущую сетку. Длина всей структуры должна быть не более длины свободного пробега. Расчет профиля барьеров с тройной сеткой приведен на рис. 2, b. На рис. 3 представлены результаты вычисления ВАХ-диодной структуры при наличии и отсутствии пленки на катоде с учетом распределения электронов по энергиям (при нуле температуры) от дна зоны проводимости до энергии Ферми $-E_{F}$. Для решения уравнения Шредингера применены метод ступенчатой аппроксимации потенциала и метод матриц передачи с использованием 120 ступенек. Плотность тока вычислялась по формуле $J=J^{+}-J^{-}$[43], где введены плотность тока с катода на анод $J^{+}$и с анода на катод $J^{-}$, подчиняющиеся уравнению

$$
J^{ \pm}=\frac{e m}{2 \pi^{2} h^{3}} \int_{E_{0}^{ \pm}}^{E_{k}^{ \pm}} D^{ \pm}\left(E_{k z}\right) d E_{k z} \int_{0}^{\infty} f^{ \pm}\left(E_{k \rho}\right) d E_{k \rho} .
$$

Здесь $E_{0}^{ \pm}-$энергии (по модулю) электронов на дне зон проводимости катода и анода, $E_{k}^{ \pm}-$ отсчитываемые от соответствующего дна кинетические энергии электрона, $D^{ \pm}-$коэффициенты прозрачности барьера слева и справа. Учитывая, что $f^{+}(E)=F(E)=$ $=\left[\exp \left(-\left(E-E_{F}\right) /(k T)\right)+1\right]^{-1}, \quad F^{-}(E)=F\left(E+e U_{a}\right)$ и определяя в цилиндрических координатах $E_{k}^{ \pm}=$ $=E_{k \rho}^{ \pm}+E_{z}^{\mu}$, имеем для плотности электронов, набегающих на барьер с обеих сторон со скоростью $v_{z}$, величины $n^{ \pm}\left(v_{z}\right)=m^{2}\left(E_{k}^{ \pm}-E_{k z}\right) /\left(2 \pi^{2} h^{3}\right)$. Для $T=0$ формулу для плотности тока тогда можно записать так:

$$
\begin{aligned}
J=\frac{e m}{2 \pi^{2} h^{3}}\left[\int_{e U_{a}}^{E_{k}^{+}}\left(E_{k}^{+}-E_{k z}\right) D^{+}\left(E_{k z}\right) d E_{k z}\right. \\
\\
\left.\quad-\int_{0}^{E_{k}^{-}}\left(E_{k}^{-}-E_{k z}\right) D^{-}\left(E_{k z}\right) d E_{k z}\right] .
\end{aligned}
$$

Здесь за нулевой уровень барьера взят уровень дна зоны проводимости анода, $E_{k}^{+}=e U_{a}+E_{F}, E_{k}^{-}=E_{F}$ (предполагается одинаковым материал катода и анода). Таким образом, основные задачи состоят в определении формы барьера и в вычислении коэффициентов прозрачности в обе стороны. Обратный ток обычно мал, и его следует учитывать только для низковольтных BAX. Решение уравнения Шредингера методом матриц передачи или численными методами обратного прохода более предпочтительны для определения $D^{ \pm}$, чем метод ВКБ, поскольку строго учитывают „хвост“ потенциала за точками поворотов, которых может быть несколько при сложной форме барьера. Результат (5) пригоден для одномерного туннелирования. В случае пространственно развитых поверхностей имеет место туннелирование по различным каналам (траекториям), вдоль которых распределение потенциала различное. Для получения интегрального тока в приближении одномерного туннелирования следует вычислять прозрачности различных таких барьеров и усреднять по траекториям, выходящим из различных эмитирующих точек поверхности [29].

\section{Туннелирование в квантово-размерных структурах углеродных кластеров}

Рассмотрим модель композитной пленки (рис. 4) из алмазных и графитовых нанокластеров радиусов $R_{1}$ и $R_{2}$, хаотически и периодически расположенных на плоской проводящей поверхности катода. Пленка с хаотическим расположением (рис. 4, $a$ ) образуется путем магнетронного напыления углерода из плазмы газового разряда низкого давления [11]. Меняя технологию напыления, можно получить двухслойную структуру с преимущественно алмазной пленкой поверх графитовой, модель которой дана на рис. 4, $b$. Соотношения алмазной и графитовой фаз и размеры кластеров зависят от параметров процесса напыления и контролировались по проводимости с использованием формулы Бруггемана и методом АСМ. Реально имеет место разброс размеров, но подбором технологии можно добиться, чтобы средние размеры кластеров находились в определенных пределах. Минимальная толщина пленки $t=\max \left(R_{1}, R_{2}\right)$ имеет место при расположении кластеров (кристаллитов) в один слой. Экспериментальное исследование эмиссии из таких структур показало [8-10], что ее максимум достигается на кластерах с размерами от 4 до $10 \mathrm{~nm}$ и при концентрации алмазной фазы порядка 70\%, при этом толщина пленки не должна превышать 20-30 nm. В такой пленке возможно расположение кластеров в один, два и три слоя. Существенное увеличение толщины до $100 \mathrm{~nm}$ не приводит к дальнейшему росту АЭ, что говорит о влиянии поверхностных эффектов в слое порядка 10-20 nm. Также эксперимент показал, что напыление алмазной фазы толщины порядка $10 \mathrm{~nm}$ поверх графитовой (рис. $4, b)$ приводит к существенному увеличению АЭ. Для моделирования удобно рассматри- 

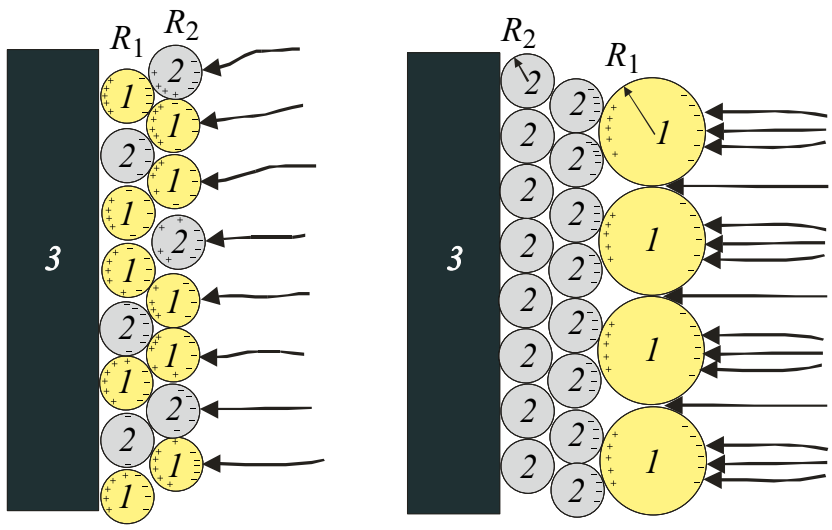

Pис. 4. Модели пленки из алмазных 1 и графитовых 2 кластеров на проводящем катоде $3: a-$ хаотически расположенные кластеры одинаковых размеров; $b-$ периодически расположенные кластеры с радиусами $R_{1}=2 R_{2}$. Отрицательные заряды на внешней поверхности способствуют выходу электронов из пленки.

вать кластеры одинакового размера, хотя реально имеет место их разброс. Наличие кластеров малых радиусов на поверхности приводит к существенному увеличению коэффициента усиления поля. При меньших размерах кластеров пленка становится более однородной и менее пористой. При больших размерах уменьшается удельная поверхность, следовательно, и число поверхностных уровней. На рассматриваемой поверхности (по сравнению с атомарно гладкой поверхностью) коэффициент усиления поля $\beta$ может быть порядка 10 и более и определяется в основном разбросом размеров кластеров. Внутри пленки поле ослаблено, особенно в графитовых кластерах, а туннелирование может идти по различным каналам. На границах кластеров 1 с катодом барьеры существенно ниже, чем для катода без пленки. На границе с вакуумом барьеры для различных каналов туннелирования различные, но также ниже барьера, возникающего на атомарно гладкой поверхности. Графитовые кластеры 2 работают как проводящие каналы, доставляющие электроны к границе и к высоким поверхностным уровням, с которых они далее туннелируют. На рис. 4 схематически показаны поверхностные заряды. Для катодов с РВ меньше, чем у графита, т.е. менее $4.5 \mathrm{eV}(\mathrm{Cu}, \mathrm{Al}$ и др.) в такой акцепторной пленке возникает отрицательный объемный заряд, приводящий к уменьшению сродства к электрону. Однако для кластеров с размерами порядка $10 \mathrm{~nm}$ нельзя говорить о зонной структуре и об отрицательном электронном сродстве (следует учитывать, что запрещенная зона в алмазе $5 \mathrm{eV}$ ). Тем не менее отрицательные объемный и поверхностный заряды способствуют выходу электрона из структуры. Сильное поле проникает на всю глубину пленки и ускоряет электроны, эмитированные непосредственно катодом и боковыми поверхностями кластеров. Такие электроны могут ускоряться как в вакууме, так и в алмазных кластерах. Строгий подход требует совместного решения уравнения Пуассона с учетом пространственного заряда и уравнения Шредингера. Модель с хаотическим расположением кластеров достаточно сложна для реализации, но модель с периодическим расположением может быть построена (см., например, [29]). Если оценить среднее поле в пленке величиной $10^{8} \mathrm{~V} / \mathrm{m}$ (существенно ниже обычного порога эмиссии), то при прохождении пленки толщины $10 \mathrm{~nm}$ электрон у барьера пленка-вакуум приобретет энергию $1 \mathrm{eV}$. Это эквивалентно снижению барьера и объясняет низкопороговую АЭ эффектом проникновения поля.

Структуры рис. 4 имеют несколько механизмов эмиссии: с поверхностей кластеров, непосредственно с катода, с поверхностных уровней. Графитовые кластеры работают как проводящие каналы, доставляющие электроны к границе с вакуумом, а также к алмазным кластерам с последующей эмиссией через их поверхности. Согласно теории протекания, концентрация таких кластеров должна быть порядка 30 и более процентов, что подтверждается экспериментом. Возможен захват электронов поверхностными уровнями с последующей их эмиссией. Большое число таких уровней, существенно превышающих энергию Ферми на катоде, сильно уменьшает порог АЭ. Экспериментально получены и исследованы АГП с толщинами 70-100 nm, в которых также проявляются перечисленные эффекты. При малой концентрации графитовых кластеров следует учитывать прыжковый механизм проводимости (туннелирование между класте-

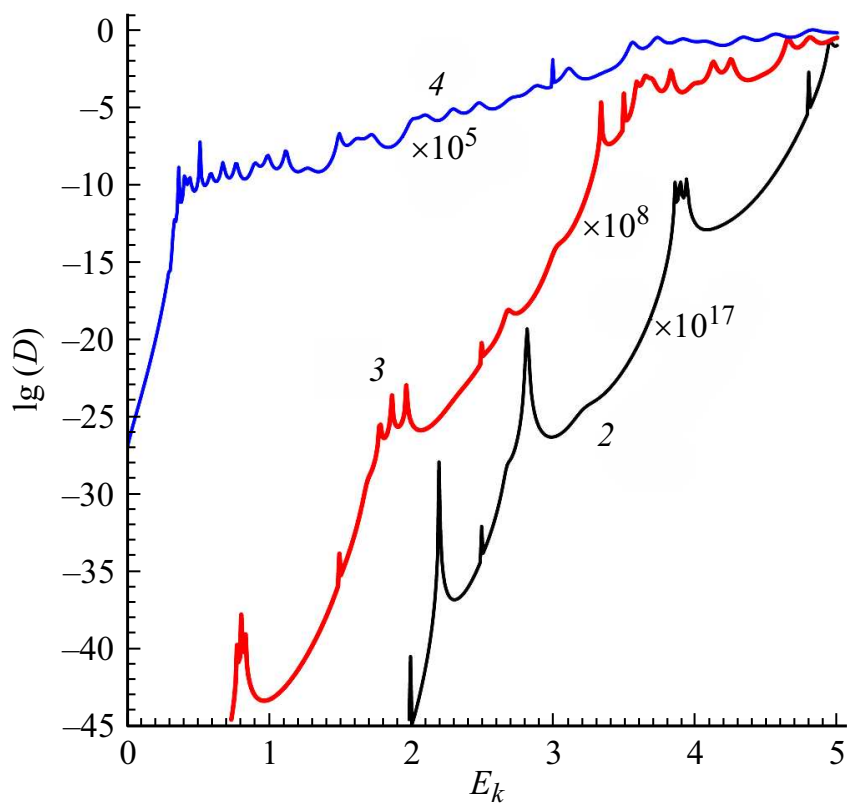

Рис. 5. Неполное резонансное туннелирование (коэффициент прозрачности $D$ в зависимости от кинетической энергии электрона) в структуре длины $30 \mathrm{~nm}$ с размером барьеров $4 \mathrm{~nm}$, зазорами в сетке $4 \mathrm{~nm}$ и межэлектродными расстояниями 2 и $8 \mathrm{~nm}$. Кривые $1-4$ соответствуют профилям барьеров $1-4$ рис. $2, b$. 
рами). Размерный эффект проявляется, когда вакуумный зазор сравним с толщиной пленки (низковольтный эмиттер). В этом случае большая часть анодного напряжения падает в вакуумном зазоре, поэтому барьер на границе пленка-вакуум существенно уже, чем в отсутствии пленки [40-42]. В качестве такого анода может выступать сетка. Ее следует наносить на слой $\mathrm{SiO}_{2}$ или другой диэлектрик, который можно делать перфорированным. Как слой, так и сетку желательно выполнять существенно тоньше, чем длина свободного пробега. В этом случае перфорация не обязательна. Слой и сетка являются структурами, удерживающими кластеры, поскольку в сильных полях пондеромоторные силы велики, и адгезии не достаточно. При расстояниях катод-сетка порядка десятков нанометров, для сильной эмиссии требуется потенциал сетки в несколько вольт. Прошедшие сетку электроны далее могут быть повернуты на 90, сфокусированы в плоский ленточный пучок и ускорены вплоть до релятивистских скоростей с целью использования в вакуумных электронных приборах $[1,73]$. При полной длине такого триода порядка $100 \mathrm{~nm}$ он может работать как THz- и ИК-транзистор. При этом высокий вакуум не нужен: достаточно заполнение при атмосферном или пониженном давлении гелием или иным газом, в котором длина свободного пробега электрона существенно превышает $100 \mathrm{~nm}$. Структуры лезвийного типа с двусторонним расположением пленок, для которых анод расположен перпендикулярно их плоскости, также исследованы. Они более устойчивы к отрыву кластеров полем, и даже после возникновения взрывной эмиссии способны восстанавливаться. Для увеличения тока пленки целесообразно напылять с обеих сторон на тонкие носители порядка 200-500 nm и делать слоистыми с вакуумными или диэлектрическими промежутками.

Экспериментальные ВАХ для рассмотренных планарных диодных структур представлены на рис. 3 (кривые 1,2 ). Они коррелируют с результатами расчета по модели однородной диэлектрической пленки с оценкой ее эффективной диэлектрической проницаемости. Повидимому, разогрев набегающих на барьер электронов в пористой структуре реальной пленки проникающим полем еще больше, что объясняет эмиссию с более низким порогом. На рис. 5 представлены результаты расчета коэффициента прозрачности для вакуумного триода с трехэлектродной сеткой. Для него имеет место неполное резонансное туннелирование, поскольку сложный барьер (рис. 2,b) имеет более высокий начальный пик. Малые значения $D$ имеют место, поскольку квазипериодические барьеры весьма протяженные с неравными высотами основного и последующих пиков. Выравнивание пиков потенциала возможно путем подачи нулевого напряжения на сетку. Такая гетероструктура с чередованием наноразмерных слоев диэлектрического и полупроводникового (металлического) типов способствует туннелированию. Имеет место как подбарьерное резонансное туннелирование, так и надбарьерное туннелирование горячих электронов.

\section{Импульсные экспериментальные ВАХ}

Исследования АЭ осуществлялись в условиях высокого вакуума $\left(10^{-5} \mathrm{~Pa}\right)$ на диодной структуре, способной изменять расстояние между электродами с точностью до $1 \mu \mathrm{m}$. Диаметр рабочей поверхности анода, изготовленного из углеродного материала МПГ-6, составлял $3 \mathrm{~mm}$. При построении импульсных ВАХ исследовано влияние длительности импульсов $(10,30,50 \mu \mathrm{s})$ и амплитуды напряжений (от $10 \mathrm{~V}$ до $3.5 \mathrm{kV}$ ) при различных частотах повторения импульсов (скважности) на порог начала АЭ, максимальные плотности автоэмиссионных токов, стабильность ВАХ в процессах тренировок и длительных импульсных измерений. Измерялись АГП с содержанием алмазной фазы 70-80\%. Понижение концентрации до 60\% уменьшает ток. Плоскости анода

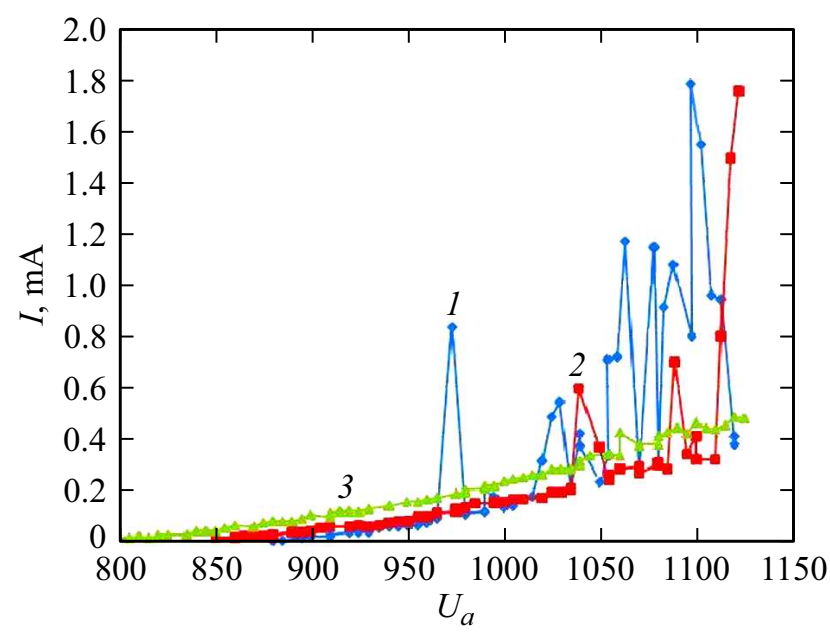

Рис. 6. Начальные участки автоэмиссионных ВАХ алмазографитовых катодных структур при различных тренировочных циклах $(1-3)$ измерений.

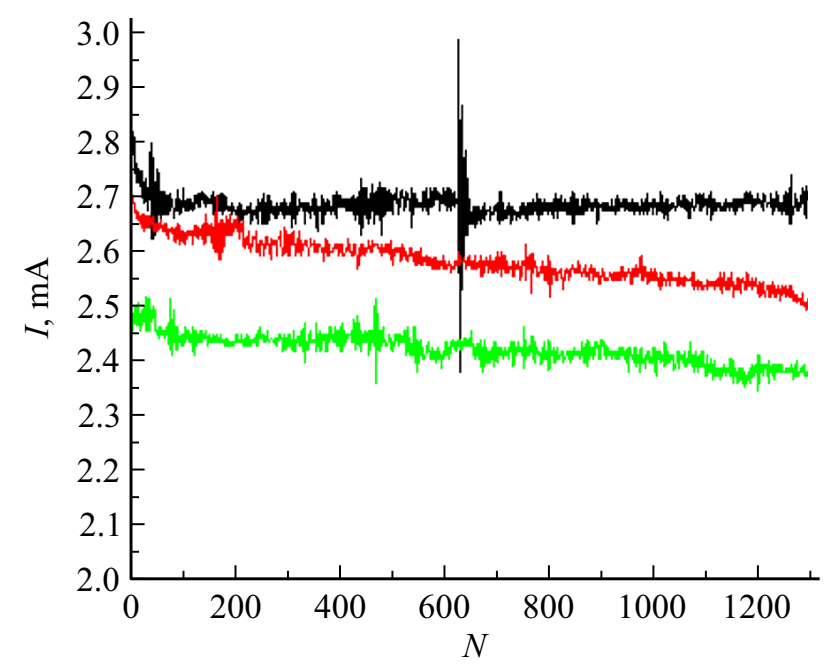

Рис. 7. Зависимости анодного тока от количества циклов измерений ВАХ низкоомной алмазографитовой пленки с амплитудой импульсов напряжений $1100 \mathrm{~V}$ при различных их длительностях: $1-10,2-30,3-50 \mu \mathrm{s}$. 


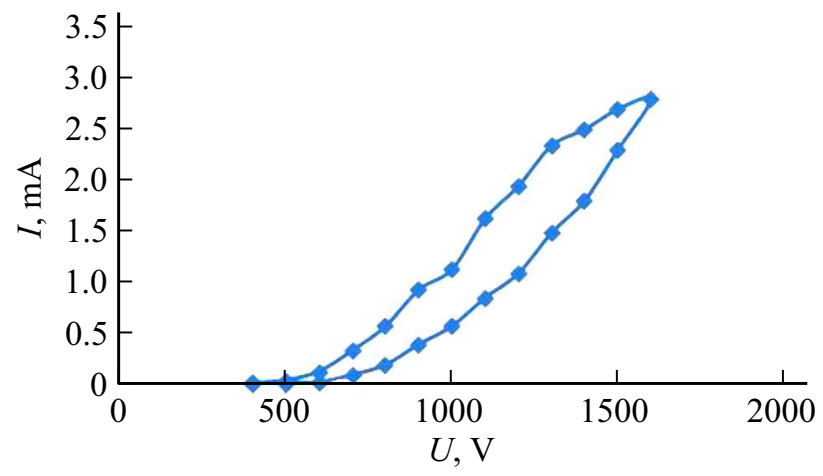

Рис. 8. Гистерезис зависимости автоэмиссионного тока от анодного напряжения $U$ при его увеличении (нижняя ветвь) и уменьшении (верхняя ветвь).

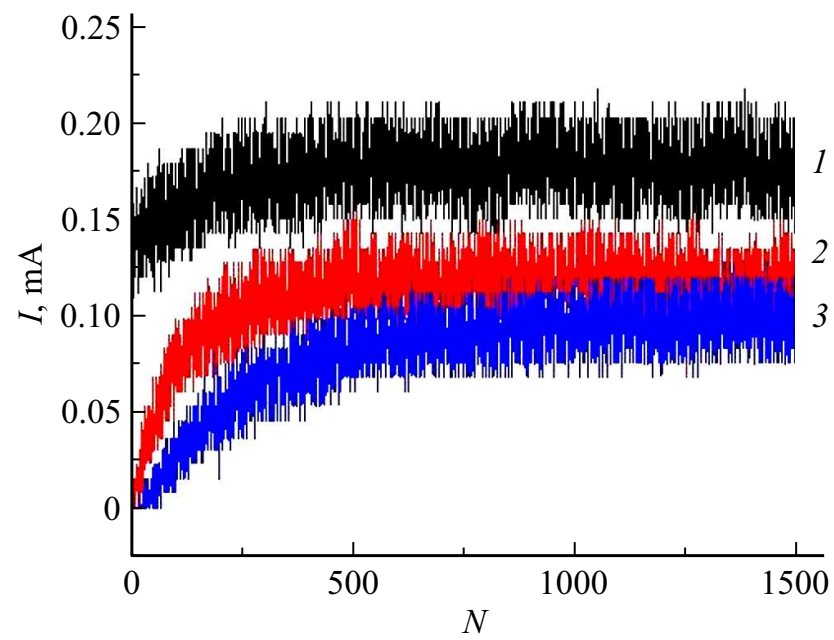

Pис. 9. Зависимости анодного тока от количества циклов $N$ измерений ВАХ низкоомной алмазографитовой пленки с амплитудой импульсов напряжений $700 \mathrm{~V}$ при различных их длительностях: 10 (1), 30 (2), $50 \mu \mathrm{s}(3)$.

и пленки были как параллельными, так и перпендикулярными. Результаты приведены для первого случая для зазора $d=20 \mu \mathrm{m}$. Пороги начала АЭ определялись по напряженности электрического поля, при которой токи АЭ составляли фиксируемую минимальную величину, равную $5 \mu \mathrm{A}$. При измерениях ВАХ минимальная амплитуда стартового импульса и интервал между возрастающими амплитудами напряжений регулировались в интервале от 10 до $100 \mathrm{~V}$. Установлено, что при импульсных автоэмиссионных измерениях с каждым последующим циклом измерений ВАХ флуктуации автоэмиссионных токов уменьшаются. Получение устойчивых и воспроизводимых ВАХ достигается, как правило, после 3-5 тренировочных циклов их проведения (рис. 6). Исследования стабильности ВАХ в процессах длительных импульсных измерений проводились при различных амплитудах напряжений и длительностях импульсов, которые оставались неизменными в течение всего цикла испытаний. При длительности испытаний в $5 \mathrm{~min}$, ко- личество использованных импульсов составляло 1500. На рис. 7 приведены зависимости анодного тока от количества циклов измерений ВАХ низкоомной АГП с амплитудой импульсов напряжений $1100 \mathrm{~V}$ и различных длительностях импульсов: $1-10 \mu \mathrm{sc} ; 2-30 \mu \mathrm{s} ; 3-50 \mu \mathrm{s}$. На рис. 8 представлены результаты, свидетельствующие о гистерезисе ВАХ.

\section{Интерпретация результатов}

По-видимому, причиной влияния длительности импульсов на построение ВАХ импульсным способом является гистерезис (рис. 9), который мы наблюдали при снятии ВАХ при медленном прямом и обратном изменении напряжения (в стационарном режиме). Впервые гистерезис импульсных ВАХ наблюдался в работе [73], где рассмотрен ступенчатый механизм АЭ. При автоэмиссии идет захват туннелирующих электронов акцепторными ловушками композитной структуры АГП (свободными поверхностными уровнями). Это формирует пространственный заряд и влияет на порог начала АЭ. При уменьшении напряжения (и АЭ тока) электроны из ловушек постепенно уходят. При больших скважностях импульсов это сказывется слабо. Накопленный электронный заряд при больших длительностях импульсов необходимо учитывать. Вид долговременных временных зависимостей является также функцией анодного напряжения, при котором образец исследуется (т.е., по существу, от величины отбираемого автоэмиссионного тока). Вблизи порога автоэмиссии $(700 \mathrm{~V})$ зависимости имеют вид, приведенный на рис. 9.

\section{Заключение}

В работе получены экспериментальные результаты измерения статических и импульсных ВАХ на вакуумных углеродных автоэмиссионных диодных структурах и произведена их интерпретация. Рассмотренные АГП в импульсном режиме демонстрируют наличие памяти (гистерезиса), связанной с туннелированием. Гистерезис доказывает, что АЭ существенным образом определяется большим числом занятых и свободных поверхностных уровней, находящихся выше уровня Ферми катода, и возникающей плотностью заряда (пространственной и поверхностной). Большую роль в этом играет пористость, способствующая также и эффекту проникновения поля. По-видимому, более строгий анализ стационарных ВАХ может дать теория, основанная на квазитрехмерном туннелировании с одновременным решением уравнений Пуассона и одномерного уравнения Шредингера вдоль заданных траекторий, при этом важны эффект проникновения поля и учет пространственного заряда. Последний - определяется многими факторами: плотностью тока, числом поверхностных уровней, электронным сродством контактирующих кластеров и катода. Учет нестационарных свойств еще более сложен. 
Для статической АЭ из диодной структуры с диэлектрической пленкой на катоде и триодной структуры с сеткой из нескольких периодически расположенных электродов получена модель АЭ на основе теории многократных изображений. Расчет для вакуумного диода с пленкой лучше соответствует эксперименту, чем для диода без пленки, что можно объяснить уменьшением и сужением барьера, а также проникновением поля в пленку. При больших напряжениях возникает наклон профиля потенциала к барьеру, что говорит об ускорении набегающего на него электрона и о приращении его кинетической энергии порядка $1 \mathrm{eV}$. Тонкие плоские структуры с двухсторонними пленками при расположении анода в перпендикулярной плоскости более устойчивы к сверхсильным полям. При расположении на них тянущей сетки возможно снятие тока со всей двусторонней поверхности с поворотом траекторий анодным напряжением и фокусировкой в ленточный пучок [74,75].

Низкопороговая АЭ обусловлена следующими эффектами: пористостью и проникновением поля, большим числом поверхностных уровней и отрицательным зарядом на поверхности кластеров, малым электронным сродством, которое при легировании может стать отрицательным. Отрицательному электронному сродству в алмазных кластерах посвящены работы [53,54,76-82]. Рассматривается допирование такими элементами, как $\mathrm{Li}, \mathrm{Mg}, \mathrm{Ag}, \mathrm{N}, \mathrm{Ni}, \mathrm{Ag}$. В частности, в [78] допировании $\mathrm{Li}$ достигнуто отрицательное сродство -1.47 , а в [82] при допировании $\mathrm{Mg}$ экстремально высокое отрицательное электронное сродство $-2.1 \mathrm{eV}$. По-видимому, основными проблемами получения больших плотностей тока из таких АГП являются удержание и охлаждение кластеров, чему может способствовать сетка, в качестве которой может служить графен.

\section{Финансирование работы}

Работа выполнена при финансовой поддержке гранта Российского научного фонда, проект № 16-19-10033.

\section{Конфликт интересов}

Авторы статьи конфликта интересов не имеют.

\section{Список литературы}

[1] Алехин Ю.В., Апин М.П., Буриев А.А., Бушуев Н.А., Воронков О.В., Григорьев Ю.А., Давидович М.В., Данилов А.Б., Исаев В.М., Кабанов И.Н., Кудряшов В.П., Куцько П.П., Мешанов В.П., Насенков И.Г., Рафалович А.Д., Роговин В.И., Рожнев А.Г., Шестеркин В.И. Сверхширокополосные лампы бегущей волны. Исследование в СВЧ-, КВЧ- и ТГЧ-диапазонах. Внедрение в производство / Под ред. Н.А. Бушуева. М.: Радиотехника, 2016. 480 с.

[2] Бобков А.Ф., Давыдов Е.В., Зайщев С.В., Карпов А.В., Козодаев М.А., Николаева И.Н., Попов М.О., Скороходов Е.Н., Суворов А.Л., Чеблуков Ю.Н. // ЖТФ. 2001. Т. 71. Вып. 6. С. 95-103.
[3] Дзбановский Н.Н., Минаков П.В., Пилевский А.А., Рахимов А.Т., Селезнев Б.В., Суетин Н.В., Юрьев А.Ю. // ЖТФ. 2005. Т. 75. Вып. 10. С. 111-114.

[4] Буриев А.А., Григорьев Ю.А., Данилушкин А.В., Наврочкий И.А., Павлов А.А., Шумихин К.В. // ЖТФ. 2018. Т. 88. Вып. 3. С. 464-471.

[5] Бурчев А.А., Павлов А.А., Кищюк Е.П., Григорьев Ю.А., Данилушкин А.В., Шумихин К.В. // Письма в ЖТФ. 2017. Вып. 11. С. 88-94.

[6] Шешин Е.П. Структура поверхности и автоэмиссионные свойства углеродных материалов. М.: МФТИ, 2001. 287 с.

[7] Тумарева Т.А., Соминский Г.Г., Поляков А.С. // ЖТФ. 2002. Т. 72. Вып. 2. С. 111-115.

[8] Карасев С.А., Симонов С.В., Суздальцев С.Ю., Яфаров Р.К. // Письма в ЖТФ. 2002. Т. 28. Вып. 23. С. 9-13.

[9] Суздальцев С.Ю., Яфаров Р.К. // ФТТ. 2004. Т. 46. Вып. 2. C. 367-371.

[10] Яфаров Р.К. // ЖТФ. 2006. Т. 76. Вып. 1. С. 42-48.

[11] Семенов А.П., Белянин А.Ф., Семенова И.А., Пащенко П.В., Барнаков Ю.А. // ЖТФ. 2004. Т. 74. Вып. 5. C. $101-104$.

[12] Ильичев Э.А., Инкин В.Н., Мигунов Д.М., Петрухин Г.Н., Полторацкий Э.А., Рычков Г.С., Шкодин Д.В. // Письма в ЖТФ. 2010. Т. 36. Вып. 4. С. 48-53.

[13] Батурин А.С., Никольский К.Н., Князев А.И., Чесов Р.Г., Шешин Е.П. // ЖТФ. 2004. Т. 74. Вып. 3. С. 62-64.

[14] Лупехин С.М., Ибрагимов А.А. // ЖТФ. 2011. Т. 81. Вып. 6. C. $109-112$.

[15] Васильева Е.А., Клещ, В.И., Образцов А.Н. // ЖТФ. 2012. Т. 82. Вып. 7. С. 107-111.

[16] Абаньшин Н.П., Горфинкель Б.И., Якунин А.Н. // Письма в ЖТФ. 2012. Т. 38. Вып. 9. С. 65-73.

[17] Гуляев Ю.В., Абаньшин Н.П., Горфинкель Б.И., Морев С.П., Резчиков А.Ф., Синищын Н.И., Якунин А.Н. // Письма в ЖТФ. 2013. Т. 39. Вып. 11. С. 63-70.

[18] Абаньшин Н.П., Горфинкель Б.И., Морев С.П., Мосияш Д.С., Якунин А.Н. // Письма в ЖТФ. 2014. Т. 40. Вып. 9. C. $86-94$.

[19] Колосько А.Г., Попов Е.О., Филиппов С.В., Романов П.А. // Письма в ЖТФ. 2014. Т. 40. Вып. 10. С. 65-72.

[20] Конакова Р.В., Охрименко О.Б., Светличный А.М, Агеев О.А., Волков Е.Ю., Коломийцев А.С., Житяев И.Л., Спиридонов О.Б. // ФТП. 2015. Т. 49. Вып. 9. C. $1278-1282$.

[21] Бушуев Н.А., Шалаев П.Д., Яфаров А.Р., Яфбаров Р.К. // Письма в ЖТФ. 2015. Т. 41. Вып. 10. С. 57-64.

[22] Абаньшин Н.П., Аветисян Ю.А., Акчурин Г.Г., Логинов А.П., Морев С.П., Мосияш Д.С., Якунин А.Н. // Письма в ЖТФ. 2016. Т. 42. Вып. 10. С. 25-32.

[23] Бенедик А.И., Крачковская Т.М., Шестеркин В.И. // ЖТФ. 2015. Т. 85. Вып. 10. С. 121-125.

[24] Бушуев Н.А., Глухова О.Е., Григорьев Ю.А., Иванов Д.В., Колесникова А.С., Николаев А.А., Шалаев П.Д., Шестеркин В.И. // ЖТФ. 2016. Т. 86. Вып. 2. С. 134-135.

[25] Плешкова Л.С., Шестеркин В.И. // ЖТФ. 2016. Т. 86. Вып. 11. С. 142-142.

[26] Архипов А.В., Габдуллин П.Г., Гордеев С.К., Журкин А.М., Квашенкина О.Е. // ЖТФ. 2012. Т. 82. Вып. 12. С. 135-144.

[27] Ябаров Р.К. // ЖТФ. 2017. Т. 87. Вып. 10. С. 1578-1578.

[28] Яфаров Р.К. // ЖТФ. 2018. Т. 88. Вып. 1. С. 127-133.

[29] Давидович М.В., Ябаров Р.К. // ЖТФ. 2018. Т. 88. Вып. 2. C. 283-293. 
[30] Яфаров Р.К. // ФТП. 2018. Т. 52. Вып. 9. С. 980-985.

[31] Яфаров Р.К. // Письма в ЖТФ. 2018. Т. 44. Вып. 13. C. $68-74$.

[32] Лупехин С.М., Ибрагимов А.А. // ЖТФ. 2012. Т. 82. Вып. 1. C. $120-125$.

[33] Бернацкий Д.П., Павлов В.Г. // Письма в ЖТФ. 2011. Т. 37. Вып. 24. С. 35-41.

[34] Ябаров Р.К., Котина Н.М. // Фундаментальные проблемы современного материаловедения. 2016. Т. 13. № 4. С. 534-539.

[35] Фурсей Г.Н., Петрик В.И., Новиков Д.В. // ЖТФ. 2009. Т. 79. Вып. 7. С. 122-126.

[36] Фурсей Г.Н., Поляков М.А., Кантонистов А.А., Яфясов А.М., Павлов Б.С., Божсевольнов В.Б. // ЖТФ. 2013. Т. 83. Вып. 6. С. 71-77.

[37] Fursey G.N. Field emission in vacuum micro-electronics. Kluwer Academic/Plenum Publishers. NY.: Springer, 2005. $205 \mathrm{p}$.

[38] Фурсей Г.Н. Автоэлектронная эмиссия. СПб.: Лань, 2012. $320 \mathrm{c}$.

[39] Давидович М.В., Яфаров Р.К. // Материалы 28й Междунар. н.-т. конф. СВЧ-техника и телекоммуникационные технологии (КрыМиКо'2018). Москва-Минск-Севастополь, 2018. С. 954-950.

[40] Davidovich M.V., Yafarov R.K., Doronin D.M. // 20th Int. Crimean Conf. Microwave and Telecommunication Technology (CriMiCo), Sevastopol, 2010. P. 733-734.

[41] Davidovich M.V., Bushuev N.A. // 2014 Tenth International Vacuum electron Sources Conference and Second International Conference on Emission Electronics. SaintPetersburg, Saint-Petersburg State University, 2014. P. 58-59.

[42] Davidovich M.V., Bushuev N.A., Yafarov R.K. // 2014 Tenth International Vacuum electron Sources Conference and Second International Conference on Emission Electronics. Saint-Petersburg, 2014. P. 67-68.

[43] Simmons J.G. // J. Appl. Phys. 1963. Vol. 34. N 6. P. $1793-1803$.

[44] Forbes R.G. // Sol. St. Electron. 2001. Vol. 45. N 6. P. 779 808.

[45] Forbes R.G., Xanthakis J.P. // Surf. Interface Anal. 2007. Vol. 39. P. 139-145.

[46] Архипов А.В., Габдуллин П.Г., Гнучев Н.М., Давыдов С.Н., Крель С.И., Логинов Б.А. // Научно-технические ведомости СПбГПУ. Физико-математические науки. 2015. № 1 (213). C. 77-92.

[47] Давидович М.В., Яфаров Р.К. // 28-я Междунар. н.-т. конф. СВЧ-техника и телекоммуникационные технологии (КрыМиКо'2018). Материалы конференции. Москва-МинскСевастополь, 2018. С. 938-948.

[48] Tristán-López F., Morelos-Gómez A., Vega-Díaz S.M., García-Betancourt M.L., Perea-López N., Elías A.L., Muramatsu H., Cruz-Silva R., Tsuruoka S., Kim Y.A., Hayahsi T., Kaneko K., Endo M., Terrones M. // ACS Nano. 2013. Vol. 7. N 12. P. 10788-10798.

[49] Mitrofanov V.V., Slepchenkov M.M., Zhang G., Glukhova O.E. // Carbon. 2017. Vol. 115. P. 803-810.

[50] Dimitrakakis G.K., Tylianakis E., Froudakis G.E. // Nano Lett. 2008. Vol. 8. P. 3166-3170.

[51] Глухова О.Е., Колесникова А.С., Слепченков М.М., Шмыгин Д.С. // ФТТ. 2015. Т. 57. Вып. 5. С. 994-998.

[52] Лобанов В.М., Шешин Е.П. // Письма в ЖТФ. 2007. Т. 33. Вып. 9. С. 11-17.
[53] Yamaguchi H., Masuzawa T., Nozue S., Kudo Y., Saito I., Koe J., Kudo M., Yamada T., Takakuwa Y., Okano K. // Phys. Rev. 2009. Vol. B80. P. 165321(5).

[54] Masuzawa T., Sato Y., Kudo Y., Saito I., Yamada T., Koh A.T.T., Chua D.H.C., Yoshino T., Chun W.J., Yamasaki S., Okano K. // J. Vac. Sci. Technol. 2011. Vol. B.29. P. 02B119-6.

[55] Koh A.T.T., Foong Y.M., Yu J., Chua D.H.C., Wee A.T.S., Kudo Y., Okano K. // J. Appl. Phys. 2011. Vol. 110. P. 034903-7.

[56] Carey J.D., Silva S.R.P. // Sol. St. Electron. 2001. Vol. 45. P. 1017-1024.

[57] Karabutov A.V., Frolov V.D., Konov V.I., Ralchenko V.G., Gordeev S.K., Belobrov P.I. // J. Vac. Sci. Technol. 2001. Vol. 19. P. 965-970.

[58] Ahmed S.F., Moon M.W., Lee K.R. // Appl. Phys. Lett. 2008. Vol. 92. P. 193502-3.

[59] Рейх К.В., Эйдельман Е.Д., Вуль А.Я. // ЖТФ. 2007. Т. 77. Вып. 7. С. 123-126.

[60] Vult A.Ya., Eidelman E.D., Dideikin A.T. Thermoelectric effect in field electron emission from nanocarbon. Synthesis, Properties and Applications of Ultrananocrystalline Diamond. NY.: Springer, 2005. Vol. 192. P. 383.

[61] Carey J.D., Silva S.R.P. // Phys. Rev. 2004. Vol. 70. N 23. Article ID 235417. P. 1-8.

[62] Arkhipov A., Davydov S., Gabdullin P., Gnuchev N., Kravchik A., Krel S. // J. Nanomaterials. 2014. Vol. 2014. Article ID 190232. P. 1-9.

[63] Давидович М.В., Ябаров Р.К. // Материалы 28-й Междунар. н.-т. конф. СВЧ-техника и телекоммуникационные технологии (КрыМиКо'2018). Москва-МинскСевастополь, 2018. С. 938-948.

[64] Федерико В.А., Шадрин В.Д. // ФТТ. 1997. Т. 39. Вып. 2. C. 2387-2391.

[65] Тамм И.Е., Блохинщев Д.И. О работе выхода электронов из металла / В кн. И.Е. Тамм. Собрание научных трудов. М.: Наука, 1975. Т. 1. С. 227-255.

[66] Фаулер Р. // УФН. 1930. Т. 10. Вып. 1. С. 135-148.

[67] Ионов А.Н., Попов Е.О., Светличный В.М., Пашкевич А.А. // Письма в ЖТФ. 2004. Т. 30. Вып. 13. С. 77-82.

[68] Макарова Т.Л. // ФТП. 2004. Т. 38. Вып. 6. С. 641-664.

[69] Song S.M., Park J.K., Sul O.J., Cho B.J. // Nano Lett. 2012. Vol. 12. P. 3887-3892.

[70] Рутьков Е.В., Лавровская Н.П., Шешеня Е.С., Галль Н.Р. // ФТП. 2017. Т. 51. Вып. 4. С. 518-523.

[71] Соболева Н.А. // УФН. 1973 Т. 111. Вып. 2. С. 321-353.

[72] Елесин В.Ф. // ЖЭТФ. 2013. Т. 144. Вып. 5. С. 1086-1098.

[73] Архипов А.В., Мишин М.В., Соминский Г.Г., Парыгин И.В. // ЖТФ. 2005. Т. 75. Вып. 10. С. 104-110.

[74] Davidovich M.V., Bushuev N.A. // 2015 25th Int. Crimean Conf. „Microwave \& Telecommunication Technology“ (CriMiCo'2015). Sevastopol, 2015. P. 145-146.

[75] Давидович М.В., Бушуев Н.А., Яфаров Р.К. // Радиотехника. 2017. № 7. С. 37-43.

[76] Krainsky I.L., Asnin V.M. // Appl. Phys. Lett. 1988. Vol. 72. N 20. P. 2554-2576.

[77] Wong K.W., Wang Y.M., Lee S.T., Kwok R.W.M. // Diamond and Related Materials. 1999. Vol. 8. P. 1885-1890.

[78] Кулова Т.Л., Евстефеева Ю.Е., Плесков Ю.В., Скундин А.М., Ральченко В.Г., Корчагина С.Б., Гордеев С.К. // ФТТ. 2004. Т. 46. Вып. 4. Р. 707-709. 
[79] Takeuchi D., Makino T., Kato H., Hirabayashi I., Okushi H., Yamasaki S. // Phys. Status Solidi 2010. Vol. 207. N 9. P. 2093-2098.

[80] Takeuchi D., Koizumi S., Makino T., Kato H., Ogura M., Ohashi H., Okushi H., Yamasaki S. // Phys. Status Solidi 2013. Vol. 210. N 10. P. 1961-1975.

[81] Protopopova V.S., Mishin M.V., Arkhipov A.V., Krel S.I., Gabdullin P.G. // Nanosystems: Physics, Chemistry Mathematics. 2014. Vol. 5. N 1. P. 178-185.

[82] O'Donnell K.M., Edmonds M.T., Tadich A., Thomsen L., Stacey A., Schenk A., Pakes C.I., Ley L. // Phys. Rev. B. 2015. Vol. 92. N 3. P. 035303-7. 